\title{
Preeclampsia serum-induced collagen I expression and intracellular calcium levels in arterial smooth muscle cells are mediated by the PLC- $\gamma 1$ pathway
}

\author{
Rongzhen Jiang, Yincheng Teng, Yajuan Huang, Jinghong Gu, Li Ma, Ming Li and Yuedi Zhou
}

In women with preeclampsia (PE), endothelial cell (EC) dysfunction can lead to altered secretion of paracrine factors that induce peripheral vasoconstriction and proteinuria. This study examined the hypothesis that PE sera may directly or indirectly, through human umbilical vein ECs (HUVECs), stimulate phospholipase C- $\gamma 1-1,4,5$-trisphosphate (PLC- $\left.\gamma 1-\mathrm{IP}_{3}\right)$ signaling, thereby increasing protein kinase $\mathrm{C}-\alpha(\mathrm{PKC}-\boldsymbol{\alpha})$ activity, collagen I expression and intracellular $\mathrm{Ca}^{2+}$ concentrations $\left(\left[\mathrm{Ca}^{2+}\right]_{\mathrm{i}}\right)$ in human umbilical artery smooth muscle cells (HUASMCs). HUASMCs and HUVECs were cocultured with normal or PE sera before PLC- $\gamma 1$ silencing. Increased PLC- $\gamma 1$ and $\mathrm{IP}_{3}$ receptor $\left(\mathrm{IP}_{3} \mathrm{R}\right)$ phosphorylation was observed in cocultured HUASMCs stimulated with $\mathrm{PE}$ sera $(\boldsymbol{P}<0.05)$. In addition, PE serum significantly increased HUASMC viability and reduced their apoptosis $(P<0.05)$; these effects were abrogated with PLC- $\gamma 1$ silencing. Compared with normal sera, $\mathrm{PE}$ sera increased $\left[\mathrm{Ca}^{2+}\right]_{\mathrm{i}}$ in cocultured HUASMCs $(P<0.05)$, which was inhibited by PLC- $\gamma 1$ and $I_{3} R$ silencing. Finally, PE sera-induced PKC- $\alpha$ activity and collagen I expression was inhibited by PLC- $\gamma 1$ small interfering RNA (siRNA) $(\boldsymbol{P}<0.05)$. These results suggest that vasoactive substances in the PE serum may induce deposition in the extracellular matrix through the activation of PLC- $\gamma 1$, which may in turn result in thickening and hardening of the placental vascular wall, placental blood supply shortage, fetal hypoxia-ischemia and intrauterine growth retardation or intrauterine fetal death. PE sera increased $\left[\mathrm{Ca}^{2+}\right]_{i}$ and induced PKC- $\alpha$ activation and collagen I expression in cocultured HUASMCs via the PLC- $\gamma 1$ pathway.

Experimental \& Molecular Medicine (2014) 46, e115; doi:10.1038/emm.2014.59; published online 26 September 2014

\section{INTRODUCTION}

Preeclampsia (PE), which is characterized by the development of pregnancy-induced hypertension and proteinuria, is a leading cause of maternal and perinatal morbidity and mortality worldwide, as well as preterm birth; ${ }^{1}$ its incidence ranges from 2 to $8 \%$ of $_{\text {pregnancies. }}^{2}$ Although some risk factors for the development of PE have been identified and include a history of PE, hypertension, renal disease, obesity and diabetes mellitus, ${ }^{3}$ the underlying cause of PE remains unknown.

We previously demonstrated that the abnormal increases in the umbilical arterial resistive and pulsatility indices (RI and PI, respectively) in early-onset severe PE were closely related to the severity of pathologic changes, including placental vascular wall thickening and lumen stenosis, placental infarction and the perinatal mortality rate. ${ }^{4}$ Increased expression of collagen I caused by the activation of protein kinase C- $\alpha$ (PKC- $\alpha)$ in the vascular smooth muscle cells (VSMCs) has an important role in the vascular changes associated with PE. ${ }^{5}$ Phospholipase
C- $\gamma 1$ (PLC- $\gamma 1$ ) is widely expressed in human cells and influences cell proliferation and differentiation. In rat aorta SMCs, the addition of low-density lipoprotein induces extracellular signal-regulated kinase phosphorylation, which is mediated by PLC and PKC. ${ }^{6}$ The activation of SMCs PLC- $\gamma 1$ phosphorylation by growth factors, including vascular endothelial growth factor and platelet-derived growth factor, ${ }^{7}$ as well as hypoxia-induced mitogenic factor, ${ }^{8}$ results in the hydrolysis of phosphatidylinositol 4,5-bisphosphate. This reaction generates 1,4,5-trisphosphate $\left(\mathrm{IP}_{3}\right)$ and 1,2-diacylglycerol (DAG), which mediate the release of $\mathrm{Ca}^{2+}$ and the activation of PKC. Dysregulation of this signaling cascade is a major cause of smooth muscle cell dysfunction; ${ }^{9}$ however, the role of PLC- $\gamma 1$ signaling in PKC- $\alpha$ activation and collagen expression is relatively unknown.

The present study was undertaken to test the hypothesis that PE serum contains soluble placenta-derived factors that may directly or indirectly, through human umbilical vein ECs

Obstetric Intensive Care Center, The Institute of Obstetrics and Gynecology, Department of Obstetrics and Gynecology, Affiliated Sixth People's Hospital, Shanghai Jiaotong University, Shanghai, China

Correspondence: Dr R Jiang, Obstetric Intensive Care Center, The Institute of Obstetrics and Gynecology, Department of Obstetrics and Gynecology, Affiliated Sixth People's Hospital, Shanghai Jiaotong University, Shanghai 200233, China. 
(HUVECs), activate the PLC- $\gamma 1-\mathrm{IP}_{3}$ pathway, thereby activating PKC- $\alpha$, inducing collagen I expression and increasing $\left[\mathrm{Ca}^{2+}\right]_{\mathrm{i}}$ in human umbilical artery smooth muscle cells (HUASMCs). The elucidation of the PLC- $\gamma 1-$ PKC- $\alpha$ pathway role in HUASMCs may help understand the etiology of PE and provide novel therapeutic targets for the prevention and treatment of PE.

\section{MATERIALS AND METHODS}

\section{Study protocol}

From March 2012 to September 2012, 40 pregnant women undergoing cesarean section in the Affiliated Sixth People's Hospital of Shanghai Jiaotong University (20 patients with PE and 20 age-matched patients with normal full-term pregnancy, similar gestational age, gravidity and parity) were enrolled after informed consent was obtained (Table 1). The patients were diagnosed with PE using welldefined criteria. ${ }^{10}$ An additional 50 normal pregnant women undergoing a cesarean section were recruited for the collection of blood samples. Patients with a history of liver, kidney or other cardiovascular diseases were excluded from this study. This study was approved by the institutional review board of the Affiliated Sixth People's Hospital. Signed informed consent was obtained from each participant.

Peripheral blood samples $(10 \mathrm{ml})$ were collected immediately after delivery from 40 pregnant women who underwent cesarean section. Umbilical vein blood samples $(50 \mathrm{ml})$ were also collected from the 50 normal pregnant women who underwent cesarean section. All blood samples were centrifuged, and the supernatant was collected and stored at $-20{ }^{\circ} \mathrm{C}$. The umbilical cord was collected from healthy full-term neonates delivered via cesarean section for the establishment of the primary cultures.

\section{Establishment of primary cultures}

Primary HUASMC cultures were established according to the tissue block culture method reported in previous studies. ${ }^{8,11}$ HUASMC cultures were confirmed by immunofluorescence analysis of the

Table 1 Baseline characteristics of the study participants

\begin{tabular}{|c|c|c|c|}
\hline & $\begin{array}{l}\text { Normal group } \\
\qquad(\mathrm{n}=20)\end{array}$ & $\begin{array}{l}\text { Preeclampsia group } \\
\qquad(\mathrm{n}=20)\end{array}$ & P-value \\
\hline \multicolumn{4}{|l|}{ Age (years) } \\
\hline Mean \pm s.d. & $28.4 \pm 5.5$ & $28.7 \pm 5.0$ & $0.836^{a}$ \\
\hline \multicolumn{4}{|c|}{ Gestational age (weeks) } \\
\hline Mean \pm s.d. & $31.6 \pm 3.0$ & $31.4 \pm 3.2$ & $0.841^{a}$ \\
\hline \multicolumn{4}{|c|}{ Gravidity, $n$ (\%) } \\
\hline 1 & $6(30.0)$ & $4(20.0)$ & $0.519^{b}$ \\
\hline 2 & $9(45.0)$ & $12(60.0)$ & \\
\hline 3 & $5(25.0)$ & $3(15.0)$ & \\
\hline 4 & $0(0.0)$ & $1(5.0)$ & \\
\hline \multicolumn{4}{|l|}{ Parity, n (\%) } \\
\hline 0 & $11(55.0)$ & $11(55.0)$ & $1.000^{\mathrm{b}}$ \\
\hline 1 & $9(45.0)$ & $8(40.0)$ & \\
\hline 2 & $0(0.0)$ & $1(5.0)$ & \\
\hline
\end{tabular}

aDetermined by an independent $t$-test.

bDetermined by a Fisher's exact test. trophoblast marker $\alpha$-actin, using an anti- $\alpha$-actin antibody followed by a PE-labeled secondary antibody (both from Santa Cruz, Dallas, TX, USA). Primary HUVEC cultures were established by the trypsin digestion method. ${ }^{12}$ The cells were cultured in Dulbecco's modified Eagle's medium supplemented with 5\% fetal bovine serum (both from Life Technologies, Carlsbad, CA, USA) and were passaged 3-4 times.

Cells in the logarithmic growth phase were collected and cultured with normal umbilical cord blood serum. After $48 \mathrm{~h}$, the medium was replaced with Dulbecco's modified Eagle's medium that contained 1\% normal umbilical vein blood serum for an additional $48 \mathrm{~h}$ before the subsequent experiments were performed.

\section{HUASMC and HUVEC coculture}

All analyses in the present study were conducted using HUASMC and HUVEC cocultures that were established as described previously. ${ }^{13}$ Briefly, $600 \mu \mathrm{l}$ of HUVECs $\left(5 \times 10^{5}\right.$ cells per well $)$ were added to the upper chamber of a Transwell $(24 \mathrm{~mm}$ Transwell with $0.4 \mu \mathrm{m}$ Pore Polycarbonate Membrane Insert; Corning, Corning, NY, USA), and $600 \mu \mathrm{l}$ HUASMCs $\left(5 \times 10^{5}\right.$ cells per well) were added to the lower chamber. The cells were cultured in Dulbecco's modified Eagle's medium that contained $20 \%$ of neonatal umbilical cord blood serum. The cells were divided into different groups after $24 \mathrm{~h}$, and subsequent experiments were performed. For each independent experiment, each assessment was performed in triplicate.

\section{PLC- $\gamma 1$ and $I P_{3} R$ siRNA transfection}

PLC- $\gamma 1$ and IP ${ }_{3} \mathrm{R}$ siRNA transfection of HUASMCs was conducted as previously described. ${ }^{14}$ Briefly, $2 \times 10^{5}$ HUASMCs were seeded in sixwell plates in the lower chamber of the Transwell. When the cells grew to $60-70 \%$ density, they were transfected with $2 \mu$ mol PLC- $\gamma 1$-siRNA (Cell Signaling, Danvers, MA, USA), IP ${ }_{3} \mathrm{R}$-siRNA (Santa Cruz) or the corresponding scrambled-siRNA via Lipofectamine 2000 Transfection Reagent (Life Technologies) and cultured for $24 \mathrm{~h}$. The medium was replaced with Dulbecco's modified Eagle's medium that contained 5\% fetal bovine serum, and the silencing efficiency was detected by western blot analysis; the cell viability was detected by MTT (3-(4,5dimethythiazol-2-yl)-2,5-diphenyl tetrazolium bromide).

\section{Detection of HUASMC viability and apoptosis}

The cells were seeded in a 96-well Transwell chamber (HTS Transwell-96 Permeable Support with $0.4 \mu \mathrm{m}$ Pore Polycarbonate Membrane; Corning). After treatment with medium that contained various concentrations of PE sera $(5,10,15,20,25$ and $30 \%$ PE sera) over different time points $(6,12,18,24,36,48$ and $72 \mathrm{~h})$, the HUASMC viability was detected by MTT (Sigma, St Louis, MO, USA).

For apoptosis detection, the cells were seeded in 6-well Transwell chambers and treated as previously described. Annexin V-FITC flow cytometry was performed using the Alexa Flour 488 Annexin V/Dead Cell Apoptosis Kit (Life Technologies) to detect HUASMC apoptosis following the manufacturer's instructions.

\section{Western blot analysis}

Extraction of HUASMC cytoplasmic and membrane proteins was performed according to a previously published method. ${ }^{12}$ The total protein was extracted using CelLytic MT cell lysis buffer (Sigma). After the samples underwent $10 \%$ sodium dodecyl sulfate-polyacrylamide gel electrophoresis, they were transferred to a nitrocellulose membrane (Bio-Rad, Hercules, CA, USA) and incubated with the following primary antibodies: PLC- $\gamma 1$, P-PLC- $\gamma 1, \mathrm{IP}_{3} \mathrm{R}$ and P-IP ${ }_{3} \mathrm{R}$ (1:1000; all from Cell Signaling, Danvers, MA, USA), PKC- $\alpha,(1: 200$, Life 
Technologies), type III procollagen (COL3A1), type I collagen (COL1A) and $\beta$-actin (1:1000, all from Santa Cruz). Following incubation at $4{ }^{\circ} \mathrm{C}$ overnight, the membrane was washed and incubated with Dye 700-fluorescein-conjugated anti-rabbit second antibody (1:4000) or IR Dye 800-fluorescein-conjugated anti-mouse second antibody (1:5000) (both from Bio-Rad) at room temperature for $1 \mathrm{~h}$. After the membranes were washed with Tris-buffered saline with Tween-20, the bands were scanned using an Odyssey Image Scanning System (LI-COR Biosciences, Lincoln, NE, USA). Quantitative analysis of the bands was performed using a Quantity One System (Bio-Rad, Hercules, CA, USA).

\section{Detection of membrane PKC activity}

Analysis of membrane PKC activity was performed using a PKC Assay Kit (Life Technologies), which measures the phosphorylation of a synthetic peptide from myelin basic protein, as previously described. ${ }^{15}$ Briefly, the protein extracts were incubated for $20 \mathrm{~min}$ at room temperature with a PKC activation preparation or a pseudosubstrate inhibitor peptide, and the incorporation of $\left[\gamma_{-}{ }^{32} \mathrm{P}\right]$ ATP into myelin basic protein was measured. The activity was calculated as the total picomoles PKC per min and normalized for cell number.

\section{Measurement of $\left[\mathrm{Ca}^{2+}\right]_{\mathrm{i}}$ concentrations}

$\left[\mathrm{Ca}^{2+}\right]_{\mathrm{i}}$ was analyzed in HUASMCs as previously described ${ }^{16}$ using Fluo-3/AM (Sigma). Briefly, the cells were seeded on coverslips and treated with calcium-free medium that contained PE serum for $2 \mathrm{~h}$ after the cells grew to $75 \%$ density. After Fluo-3/AM ( $5 \mu \mathrm{M})$ was added to the calcium-free medium, the cells were incubated at $37^{\circ} \mathrm{C}$ for $30 \mathrm{~min}$ in the dark. The cells were washed two times with physiologic extracellular fluid (141 mm NaCl, $4.7 \mathrm{~mm} \mathrm{KCl,} 1.2 \mathrm{~mm} \mathrm{MgCl}_{2}, 10 \mathrm{~mm}$ glucose, 10 mM HEPES, pH 7.4), and 20 cells were selected from each group. A laser confocal microscope (MRC-1024; Bio-Rad, Hercules, CA, USA) was used to observe the fluorescence intensity. Each cell was scanned once every $2 \mathrm{~s}$, and 15 scans were performed.

\section{Statistical analysis}

The continuous data are presented as the mean \pm standard deviations, and the categorical data are summarized as numbers and percentages.

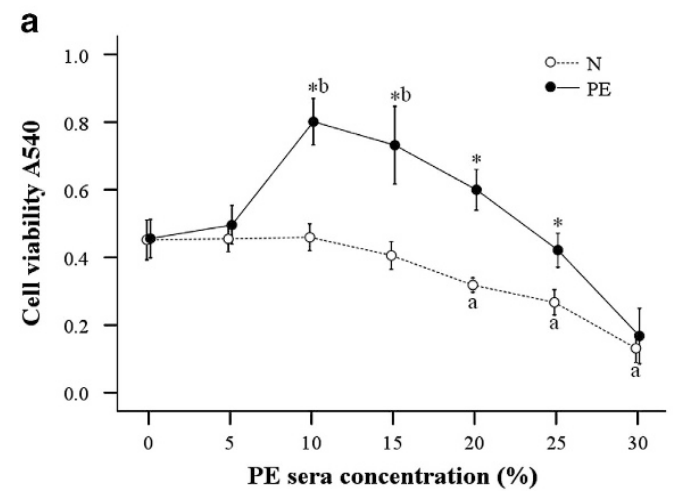

The comparisons in the baseline characteristics between the subjects with normal pregnancy $(\mathrm{N})$ and the subjects with PE were performed using an independent $t$-test for continuous data and a Fisher's exact test for categorical data. The effects of different PE serum concentrations or different time points on cell viability were evaluated using one-way analysis of variance. Pairwise post hoc tests using Bonferroni correction were applied when significant findings were identified by analysis of variance. The comparisons in cell viability, apoptosis rate, relative protein expression and fluorescence intensity were performed using an independent $t$-test between two independent groups ( $\mathrm{N}$ vs PE; N vs PE+PLC- $\gamma 1$ siRNA) and using a paired $t$-test between two dependent groups (PE vs PE+PLC- $\gamma 1$ siRNA; PE vs PE $+\mathrm{IP}_{3} \mathrm{R}$ siRNA). Bonferroni corrections were applied to control the overall type I error when conducting multiple comparisons. The statistical analyses were performed with SAS software version 9.2 (SAS Institute, Cary, NC, USA). A two-tailed $P<0.05$ indicated statistical significance.

\section{RESULTS}

Effects of PE serum on the viability of cocultured HUASMCs In our previous study, PE serum enhanced the proliferation and reduced the apoptosis of HUASMCs in the presence and absence, respectively, of cocultured HUVECs. ${ }^{10}$ Because cocultures of HUVECs and HUASMCs mimic the pathogenesis of placental artery abnormalities in PE, we performed all experiments in the present study using cocultures. The cocultured HUASMCs were treated with medium that contained various concentrations of PE sera for $24 \mathrm{~h}$. The cell viability in the PE group was significantly higher compared with the normal group $(\mathrm{N})$ at the $\mathrm{PE}$ serum concentrations of $10-25 \%$ $(P<0.001)$; the optimal cell viability was obtained with medium that contained $10 \%$ PE serum $(P<0.001$ compared with other concentrations with the exception of $15 \%$; Figure 1a). Therefore, this concentration of sera was selected for subsequent experiments. The cocultured cells were then cultured with $10 \% \mathrm{PE}$ serum for various time points. As shown in Figure $1 b$, cell viability in the PE group was significantly higher compared with the $\mathrm{N}$ group at $12-48 \mathrm{~h}(P<0.001)$, and

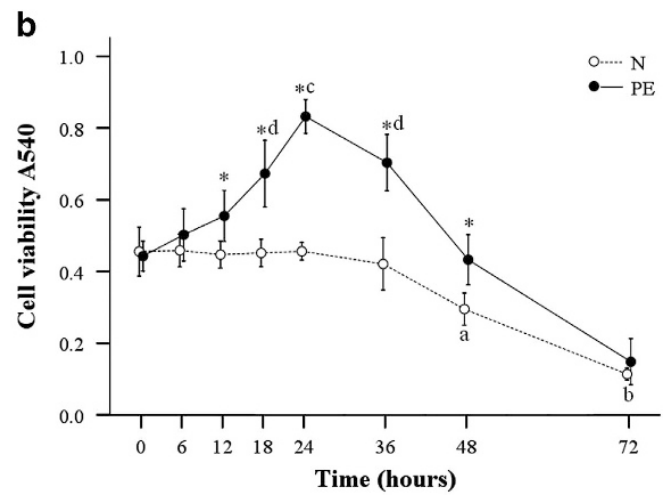

Figure 1 Effects of preeclampsia (PE) serum on the viability of cocultured human umbilical artery smooth muscle cells (HUASMCs). (a) HUASMC viability was measured following incubation with the indicated concentration of PE sera after $24 \mathrm{~h}$. ${ }^{*}$ The cell viability was significantly higher in the PE group compared with the normal (N) group. aSignificantly lower compared with the 0-15\% points in the N group. bSignificantly higher compared with the $0,5,20,25$ and $30 \%$ points in the PE group. (b) HUASMC viability was measured following incubation with $10 \%$ PE sera at the indicated time points. Data are presented as the mean \pm s.d. of eight measurements. ${ }^{*}$ The cell viability was significantly higher in the PE group compared with the $\mathrm{N}$ group. aSignificantly lower compared with the 0-36 h time points (in the $\mathrm{N}$ group). ${ }^{b}$ Significantly lower compared with the $0-48 \mathrm{~h}$ time points (in the $\mathrm{N}$ group). 'Significantly higher compared with all other time points. dSignificantly higher compared with the 0-12 and 48-72 $\mathrm{h}$ time points. 


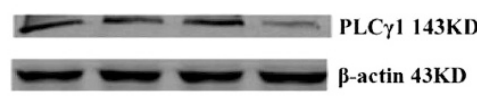

Ctr Lip2000 Scrambled PLC $\gamma 1$ SiRNA
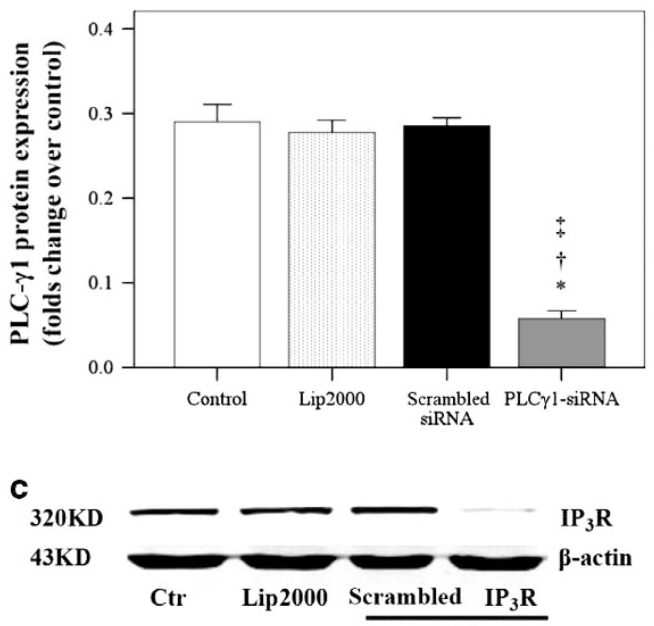

SiRNA

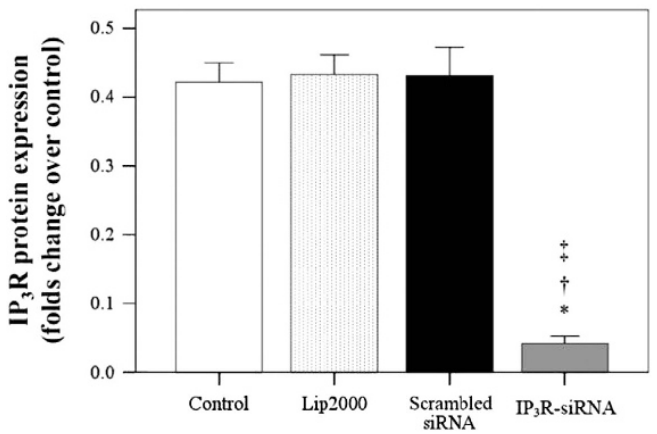

b

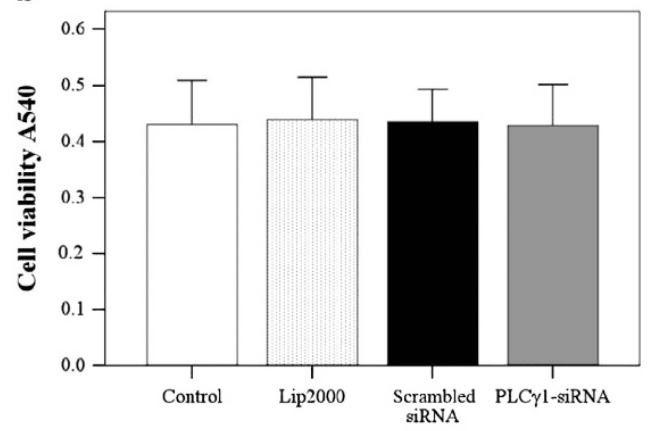

d

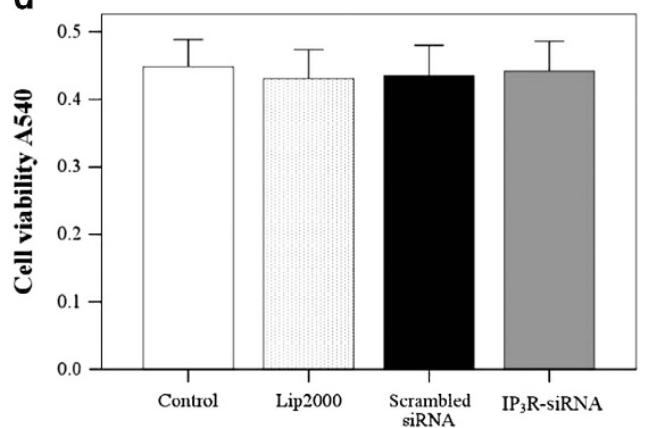

Figure 2 Effects of phospholipase $\mathrm{C}-\gamma 1$ (PLC- $\gamma 1$ ) small interfering RNA (siRNA) and 1,4,5-trisphosphate receptor (IP ${ }_{3} R$ ) siRNA on cocultured human umbilical artery smooth muscle cell (HUASMC) viability. (a) PLC- $\gamma 1$ and (c) IP $P_{3}$ expression was determined in HUASMCs following transfection with the indicated siRNAs. The data represent five samples per group. (b and $\mathbf{d})$ The effects of (b) PLC- $\gamma 1$ and (d) $I P_{3} R$ siRNA on HUASMC viability. Data are presented as the mean \pm s.d. of at least five independent experiments. Significantly different from the ${ }^{*}$ control (Ctr), ${ }^{\dagger}$ Lip2000 and ${ }^{\ddagger}$ scrambled siRNA groups, $P<0.05$.

the cell viability was greatest at $24 \mathrm{~h}(P<0.001$ compared with the other time points). Therefore, the cells were cocultured in $10 \% \mathrm{PE}$ serum for $24 \mathrm{~h}$ in subsequent experiments.

Effects of PLC- $\gamma 1$ siRNA on cocultured HUASMC viability The silencing effects of PLC- $\gamma 1$ siRNA and $\mathrm{IP}_{3} \mathrm{R}$ siRNA in HUASMCs were subsequently determined. As shown in Figures $2 \mathrm{a}$ and $\mathrm{c}$, PLC- $\gamma 1$ and $\mathrm{IP}_{3} \mathrm{R}$ were significantly decreased in the PLC- $\gamma 1$-siRNA and $\mathrm{IP}_{3} \mathrm{R}$ groups, respectively $(P<0.05)$. However, as shown in Figures $2 \mathrm{~b}$ and $\mathrm{d}$, the cell viability did not change $(P>0.05)$.

PE serum activated the PLC- $\gamma 1-\mathrm{IP}_{3} \mathrm{R}$ pathway in cocultured HUASMCs

As shown in Figure 3a, the PE group had significantly higher relative p-PLC- $\gamma 1$ levels compared with the other three groups $(P<0.001)$; the PLC- $\gamma 1$ expression was significantly decreased in the N+PLC- $\gamma 1$-siRNA group compared with the $\mathrm{N}$ group and was significantly decreased in the PE+PLC- $\gamma 1$-siRNA group compared with the PE group $(P<0.001)$. The $\mathrm{p}-\mathrm{IP}_{3} \mathrm{R}$ levels were consistently and significantly higher in the PE group compared with the N, N+PLC- $\gamma 1$-siRNA and PE+PLC $\gamma 1$ siRNA groups (Figure $3 \mathrm{~b} ; P<0.001$ ). No difference was identified in the relative protein expression of $\mathrm{IP}_{3} \mathrm{R}$ among the four treatment groups (Figure $3 \mathrm{~b} ; P>0.05$ ).

\section{PE serum increased the proliferation of cocultured HUASMCs and reduced their apoptosis}

The HUASMC viability and apoptosis were determined after treatment with normal serum $(\mathrm{N})$, normal serum in addition to PLC- $\gamma 1$ siRNA, PE serum and PE serum in addition to PLC- $\gamma 1$ siRNA. The cells treated with PE had significantly higher viability (Figure 4a; $P<0.001$ ) and lower apoptosis (Figure $4 \mathrm{~b} ; P<0.001$ ) compared with the cells cultured with normal serum. Moreover, the effects of PE serum on HUASMC viability and apoptosis were abrogated with PLC- $\gamma 1$ siRNA (Figure 4; $P<0.001$ ). 
a
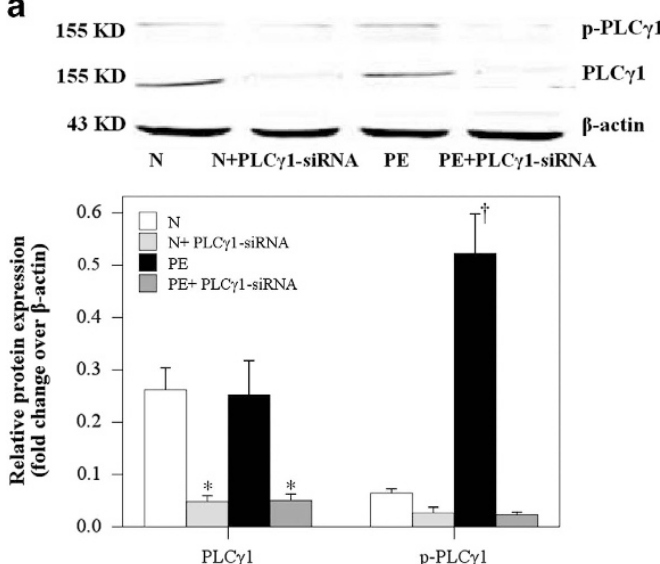

b
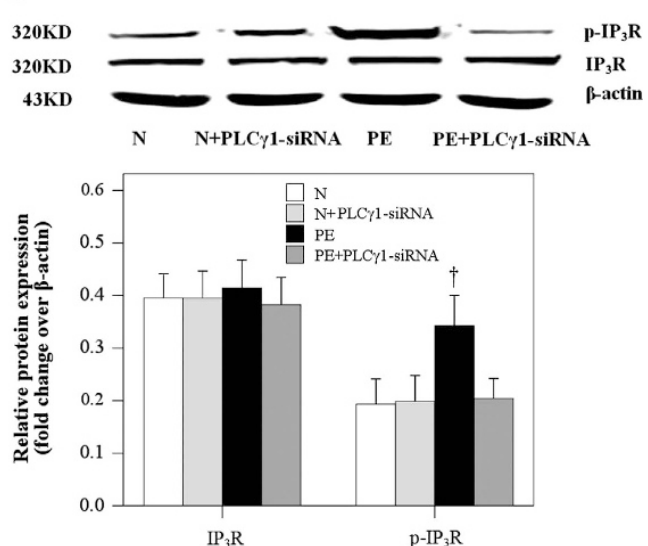

Figure 3 Preeclampsia (PE) serum promoted phospholipase $C-\gamma 1$ (PLC- $\gamma 1$ ) and 1,4,5-trisphosphate receptor (IP $\left.{ }_{3} R\right)$ phosphorylation of the cocultured human umbilical artery smooth muscle cells (HUASMCs). Western blot analysis of (a) PLC- $\gamma 1$ and (b) IP ${ }_{3} R$ phosphorylation or total (a) PLC- $\gamma 1$ and (b) $I P_{3} R$ expression in the cocultured HUASMCs following treatment with normal (N) or PE sera with or without PLC- $\gamma 1$ small interfering RNA (siRNA). Data are presented as the mean \pm s.d. of 20 samples per group. * Significantly different compared with the $\mathrm{N}$ and $\mathrm{PE}$ groups, $P<0.001$. ${ }^{\dagger}$ Significantly different compared with the other three groups, $P<0.001$.

Effects of $\mathrm{IP}_{3} \mathrm{R}$ siRNA on $\left[\mathrm{Ca}^{2+}\right]_{i}$ in cocultured HUASMCs Analysis of the fluorescence intensity revealed that $\mathrm{PE}$ sera significantly increased the $\left[\mathrm{Ca}^{2+}\right]_{\mathrm{i}}$ compared with the $\mathrm{N}$ group (Figure 5b; $P<0.001$ ). The effects of PE sera were significantly inhibited with both PLC $\gamma 1$ siRNA and $\mathrm{IP}_{3} \mathrm{R}$ siRNA $(P<0.001)$ to similar levels observed in the $\mathrm{N}$ group. No differences in $\left[\mathrm{Ca}^{2+}\right]_{\mathrm{i}}$ were observed in the normal group after knockdown of PLC- $\gamma 1$ or $\mathrm{IP}_{3} \mathrm{R}$ (Figure 5b). Representative images for each treatment group are shown in Figure 5a.

Effects of PE serum and PLC- $\gamma 1$ siRNA on PKC- $\alpha$ activity and collagen I expression by cocultured HUASMCs Cytosolic PKC- $\alpha$ (c-PKC- $\alpha$ ) activity was significantly lower in the PE group compared with the $\mathrm{N}$ group $(P<0.001)$, which was abrogated with PLC- $\gamma 1$ silencing (Figure $6 \mathrm{a} ; \mathrm{P}<0.001$ ). However, membrane PKC- $\alpha$ expression was significantly higher in the $\mathrm{PE}$ group compared with the $\mathrm{N}$ group (Figure 6a; $P<0.001$ ). Again, no differences were observed between the PE+PLC- $\gamma 1$ siRNA and $\mathrm{N}$ groups $(P>0.05)$. As shown in Figure $6 \mathrm{~b}, \mathrm{PKC}-\alpha$ activity was significantly higher in the PE group compared with the $\mathrm{N}$ group $(P<0.001)$. Although the PE+PLC- $\gamma 1$ siRNA group had significantly lower PKC- $\alpha$ activity compared with the PE group $(P<0.001)$, it remained significantly higher compared with the $\mathrm{N}$ group $(P=0.009)$.

Because PKC- $\alpha$-induced collagen I expression in VSMCs has an important role in the vascular changes associated with $\mathrm{PE}{ }^{5}$ we subsequently analyzed the effects of PE sera on collagen I expression by cocultured HUASMCs. The analysis of relative type I collagen expression revealed a significant increase in the PE group (Figure 6c; $P<0.001$ ), which was inhibited by PLC- $\gamma 1$ siRNA $(P<0.001)$ but not $\mathrm{IP}_{3} \mathrm{R}$ siRNA. No difference in the relative expression of type III procollagen was observed among the three treatment groups (Figure $6 c ; P>0.05$ ).

\section{DISCUSSION}

Altered EC secretion of factors into the serum in PE patients can induce peripheral vasoconstriction and proteinuria. ${ }^{5}$ This study analyzed the effects of PE sera on PLC- $\gamma 1-\mathrm{PI} 3$ signaling, PKC- $\alpha$ activity, collagen I expression and $\left[\mathrm{Ca}^{2+}\right]_{\mathrm{i}}$ in HUASMCs cocultured with HUVECs. PLC- $\gamma 1$ siRNA could reverse the $\mathrm{PKC}-\alpha$ activation and collagen I expression induced by $\mathrm{PE}$ serum. These results suggest that vasoactive substances in the PE serum may induce deposition in the extracellular matrix (ECM) through the activation of PLC- $\gamma 1$, which may in turn result in thickening and hardening of the placental vascular wall, placental blood supply shortage, fetal hypoxia-ischemia and intrauterine growth retardation or intrauterine fetal death.

Both VSMCs and ECs have key roles in the pathogenesis of hypertensive vascular diseases, including PE. Following vascular EC death or injury, inotropic agents, including angiotensin-II (Ang-II) ${ }^{17}$ and endothelin-1 (ET-1), ${ }^{18}$ may be released, which may induce spasmodic contraction and/or migration of VSMCs. Subsequent extensive ECM remodeling results in the vascular intima thickening and stenosis characteristic of vascular disease, which may shrink the arterial wall ${ }^{19}$ and increase peripheral resistance and fetal blood pressure. ${ }^{20}$ Specifically, increased type I collagen synthesis has been identified in pulmonary hypertension vascular remodeling, ${ }^{21}$ as well as in sympathetic ventricular wall remodeling. ${ }^{22}$ Furthermore, in PE patients, subintimal migration of umbilical cord VSMCs that synthesize a large amount of ECM (primarily type I collagen) is closely associated with the thickening and stenosis of the vascular wall. ${ }^{23}$ Collagen accumulation may also result from suppressed collagen degradation ${ }^{20}$ because reduced matrix metalloproteinase- 2 and matrix metalloproteinase- 9 were observed in an in vivo model of reduced uteroplacental perfusion pressure. ${ }^{24}$ In the present study, PE sera increased cocultured HUASMC proliferation and collagen I expression, which is consistent with previous reports $5,25,26$ that have described a role for the PKC-nuclear factor- $\kappa \mathrm{B}$ signaling 
a
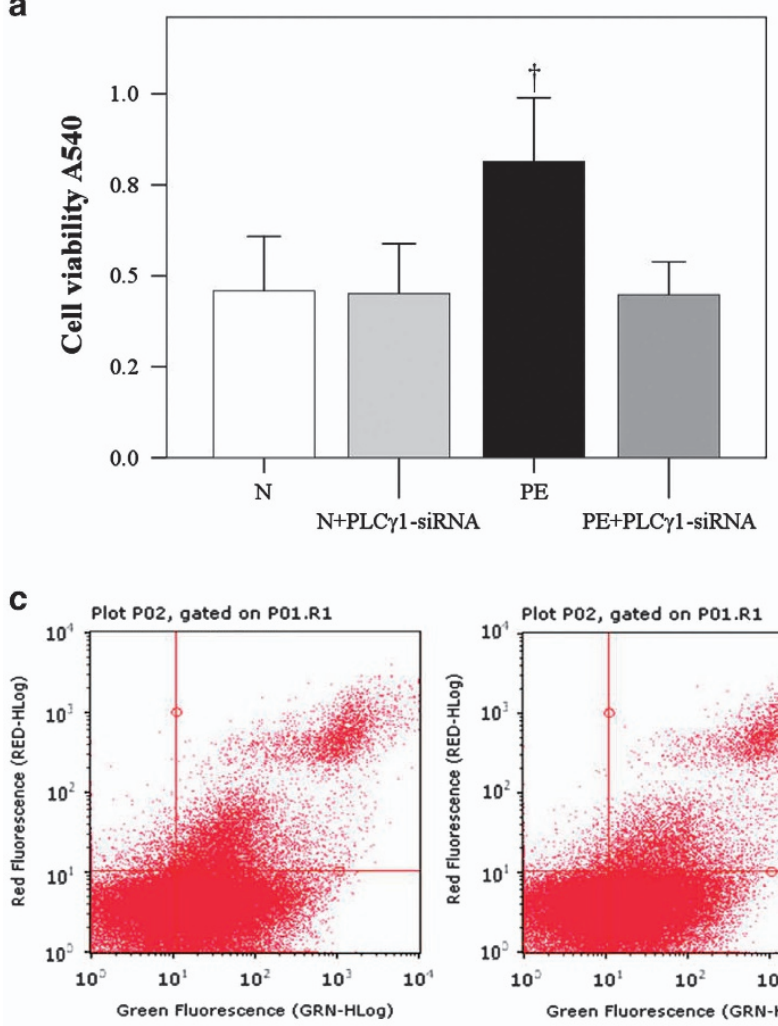

$\mathrm{N}$

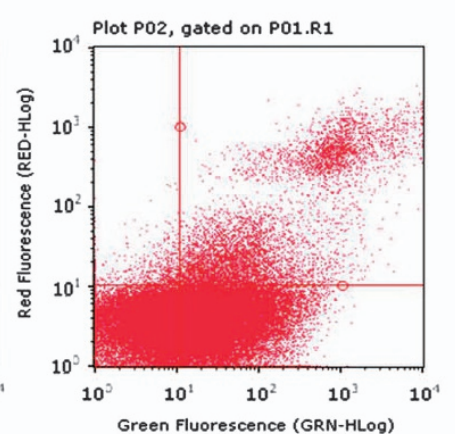

$\mathrm{N}+\mathrm{PLC} \gamma 1$-siRNA

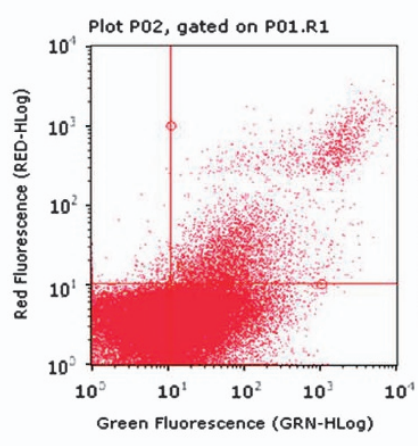

PE
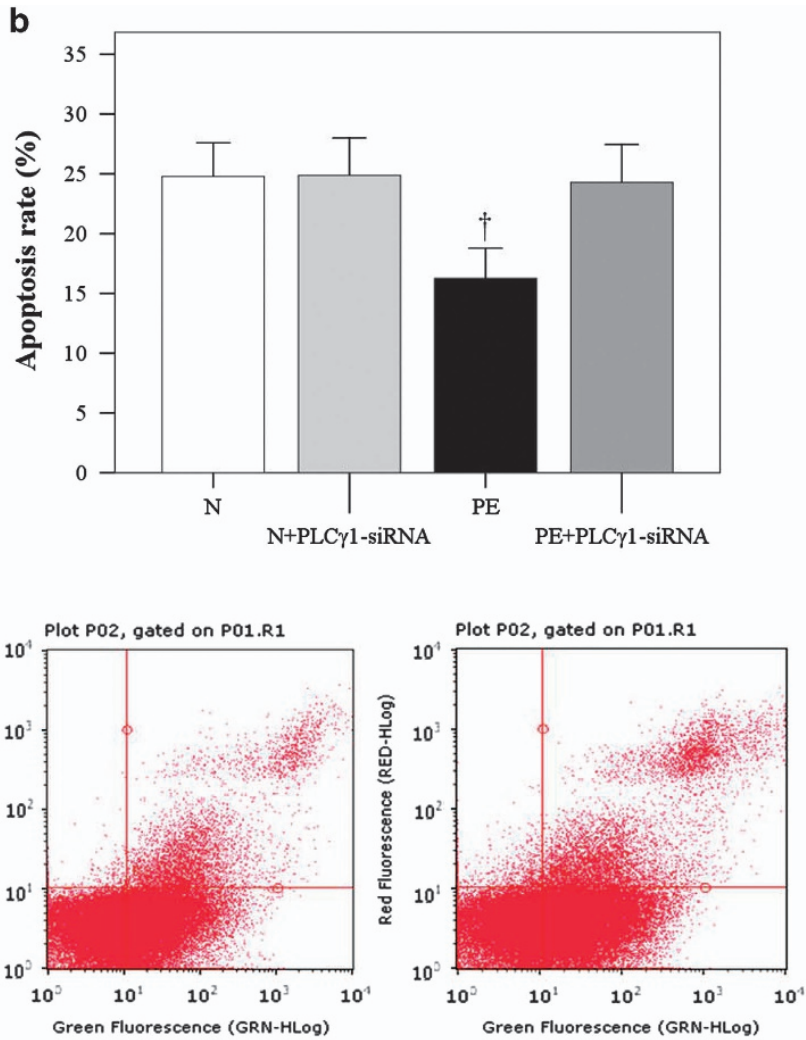

PE+ PLC $\gamma 1$-siRNA

Figure 4 Preeclampsia (PE) serum promoted the proliferation and reduced the apoptosis of cocultured human umbilical artery smooth muscle cells (HUASMCs). HUASMC (a) viability and (b) apoptosis was determined after coculture with HUVECs and treatment with normal (N) or PE sera. (c) Flow cytometry analysis of HUASMC apoptosis. Data are presented as the mean \pm s.d. of 20 samples per group. †Significantly different compared with the other three groups, $P<0.001$. PLC- $\gamma 1$, phospholipase $\mathrm{C}-\gamma 1$.

pathway in this process. The increased collagen I expression by PE sera was abrogated by PLC- $\gamma 1$ siRNA, but not IP ${ }_{3} \mathrm{R}$ siRNA, which suggests that PKC activity may be required for collagen I expression. Because Ang-II-mediated expression of p21activated kinase 1 in VSMCs was dependent on both intracellular $\mathrm{Ca}^{2+}$ mobilization and $\mathrm{PKC},{ }^{27}$ further studies will assess the role of nuclear factor- $\mathrm{kB}$-mediated gene expression, as well as PKC $\delta$ in this process.

Increased type III collagen has been observed in PE umbilical cord veins. ${ }^{20}$ In addition, the culture of adventitial fibroblasts with conditioned media from tumor growth factor- $\beta$-treated SMCs induced collagen-3 but not collagen-1 expression. ${ }^{28}$ Therefore, we analyzed the effects of PE sera on precollagen III synthesis by cocultured HUASMCs and observed no difference compared with normal sera. Further studies will determine if the PE sera contains factors that directly or indirectly influence collagen synthesis or degradation in PE, including matrix metalloproteinases, platelet-derived growth factor, tumor growth factor- $\beta$ and tumor necrosis factor- $\alpha$ $(\mathrm{TNF}-\alpha) .{ }^{26}$ The role of the tumor growth factor- $\beta / \mathrm{Smad} 3$ pathway will also be explored in detail. ${ }^{29}$

Because of the role of apoptosis in the placenta in normal pregnancy, ${ }^{30}$ we also analyzed the effects of PE sera on apoptosis in cocultured HUASMCs. PE sera reduced HUASMC apoptosis, which was inhibited by PLC- $\gamma 1$ siRNA. This effect is different from the apoptosis-inducing activity reported for PKC $\delta$ in PE placentas, which induces Bax dissociation from $14-3-3 \xi^{31}$

In the present study, PE sera-induced PKC- $\alpha$ activation was inhibited with PLC- $\gamma 1$ siRNA. Snetkov et al. ${ }^{32}$ described a role for PLC in the mediation of PKC activation in VSMCs, thereby having an important role in activator-induced vascular contraction, as well as the synthesis and deposition of ECM. Moreover, VSMC activators, such as Ang-II and ET-1, can activate PLC, ${ }^{12}$ and the subsequent hydrolysis of phosphatidylinositol 4,5-bisphosphate yields $\mathrm{IP}_{3}$ and DAG. $\mathrm{IP}_{3}$ may induce cell contraction via an increase in $\left[\mathrm{Ca}^{2+}\right]_{i}$ as the binding of $\mathrm{Ca}^{2+}$ to calmodulin activates myosin light-chain kinase, which leads to the phosphorylation of myosin light chain and the subsequent activation of myosin ATPase. ${ }^{33}$ In addition, increased DAG may result in persistent PKC activation and therefore continuous SMC contraction, as well as mitogenactivated protein kinase kinase activation via Raf-1 and mitogen-activated protein kinase, which may increase ECM synthesis in VSMCs. ${ }^{9}$ Thus, the PLC-phosphatidylinositol 4,5-bisphosphate- $\mathrm{IP}_{3}$ and DAG signaling pathways can not only induce SMC contraction via PKC activation but also ECM synthesis. 
a

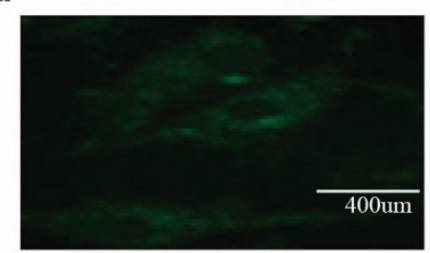

$\mathrm{N}$

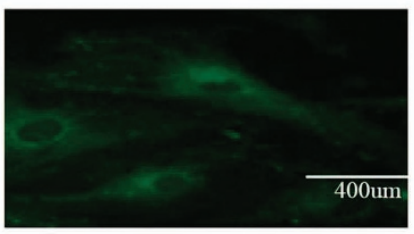

PE

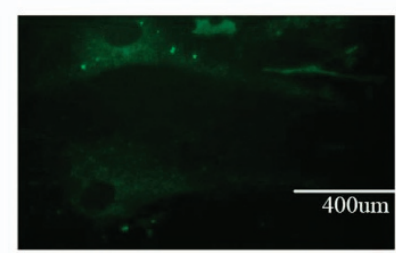

$\mathrm{N}+\mathrm{PLC} \quad \gamma 1$ siRNA

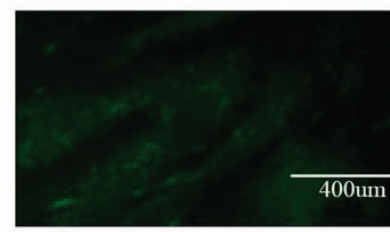

PE +PLC $\gamma 1$ siRNA

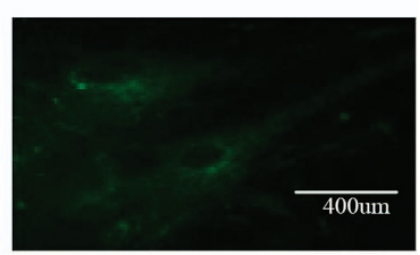

$\mathrm{N}+\mathrm{IP} 3 \mathrm{R}$ sRNA

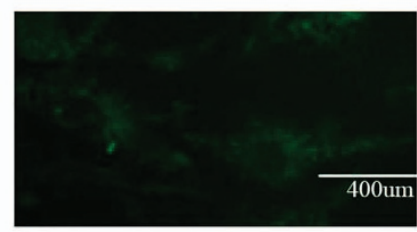

PE +IP3R SRNA

b

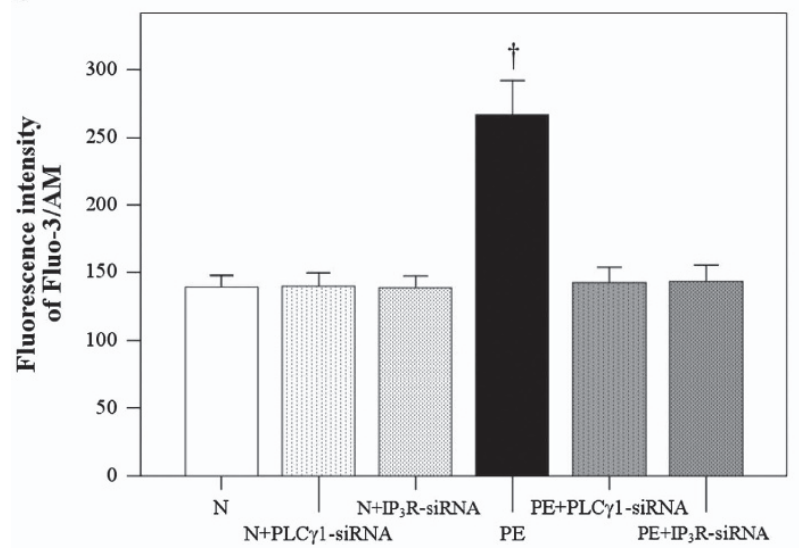

Figure 5 Inhibition of preeclampsia (PE)-induced calcium influx in cocultured human umbilical artery smooth muscle cells (HUASMCs) by phospholipase C- $\gamma 1$ (PLC- $\gamma 1$ ) and 1,4,5-trisphosphate receptor ( $\mathrm{PP}_{3} \mathrm{R}$ ) small interfering RNA (siRNA). (a) Calcium accumulation in the HUASMCs treated with normal (N) serum, N+PLC- $\gamma 1$-siRNA serum, N+IP 3 R-siRNA serum, PE serum, PE+PLC- $\gamma 1$-siRNA serum and PE $+I P_{3} R$-siRNA serum. (b) Fluorescence intensity of calcium influx in the cocultured HUASMCs. Data are presented as the mean \pm s.d. of 20 samples per group. ${ }^{\dagger}$ Significantly different compared with the other five groups, $P<0.001$.

Given the role of altered calcium signaling and the loss of nitric oxide synthesis by VSMCs in $\mathrm{PE}^{34,35}$ and the potential role of calcium nutritional deficiency in $\mathrm{PE},{ }^{36,37}$ the effects of PE sera on calcium homeostasis were analyzed. PE sera increased $\left[\mathrm{Ca}^{2+}\right]_{\mathrm{i}}$, which was mediated by the PLC- $\gamma 1-\mathrm{PKC}-\alpha$ pathway. These results are consistent with Krupp et al. ${ }^{38}$ who reported an increased $\left[\mathrm{Ca}^{2+}\right]_{\mathrm{i}}$ in response to arachidonic acid by PE HUASMCs. Moreover, calcium pretreatment inhibited EC activation by necrotic trophoblastic debris, as well as PE sera, and these protective effects were inhibited by a nitric oxide synthase inhibitor. ${ }^{39}$ Further studies will assess the effects of PLC- $\gamma 1-$ PKC- $\alpha$ pathway inhibition on calcium homeostasis in PE.

PE sera increased the $\left[\mathrm{Ca}^{2+}\right]_{\mathrm{i}}$ in cocultured HUASMCs and peaked at $2 \mathrm{~h}$ (data not shown). This delayed response may, at least in part, be because of the transwell coculture system that has been used. Because Green et al. ${ }^{40}$ reported that PE serum did not increase $\mathrm{Ca}^{2+}$ levels in HUASMCs cultured alone, we anticipate that HUVEC coculture is necessary to observe PE sera-induced increases in $\left[\mathrm{Ca}^{2+}\right]_{\mathrm{i}}$.
Although the present study did not determine the molecule in the PE sera that induced the responses in HUASMCs either directly or indirectly via HUVECs, Steinert et al. ${ }^{37}$ suggested that a monooxygenase metabolite may be responsible for the increased $\left[\mathrm{Ca}^{2+}\right]_{\mathrm{i}}$ observed in PE HUASMCs. Moreover, the presence of inotropic vasoactive substances, including Ang-II and ET-1, in the serum of PE patients has been detected; ${ }^{41-44}$ however, it is not clear whether these substances are derived from the placenta or injured vascular ECs. ET-1 can regulate smooth muscle cell proliferation ${ }^{45}$ and induce endoplasmic reticulum stress via the PLC-IP 3 pathway in $\mathrm{PE}_{3}^{46}$ however, ET-1 or Ang-II alone fails to explain the pathogenesis of vascular disease in PE patients. In addition, whether the vasoactive substances in the serum of PE patients exert their effects via the induction of VSMC contraction and ECM synthesis in a PLC-phosphatidylinositol 4,5-bisphosphate- $\mathrm{IP}_{3}$ and DAG-dependent manner remains unclear. Given the effects of PE sera on the induction of type I collagen expression via PKC-nuclear factor- $\mathrm{KB}$ signaling, ${ }^{5,24}$ additional paracrine mediators may be responsible for the activation of the cis- and 
a
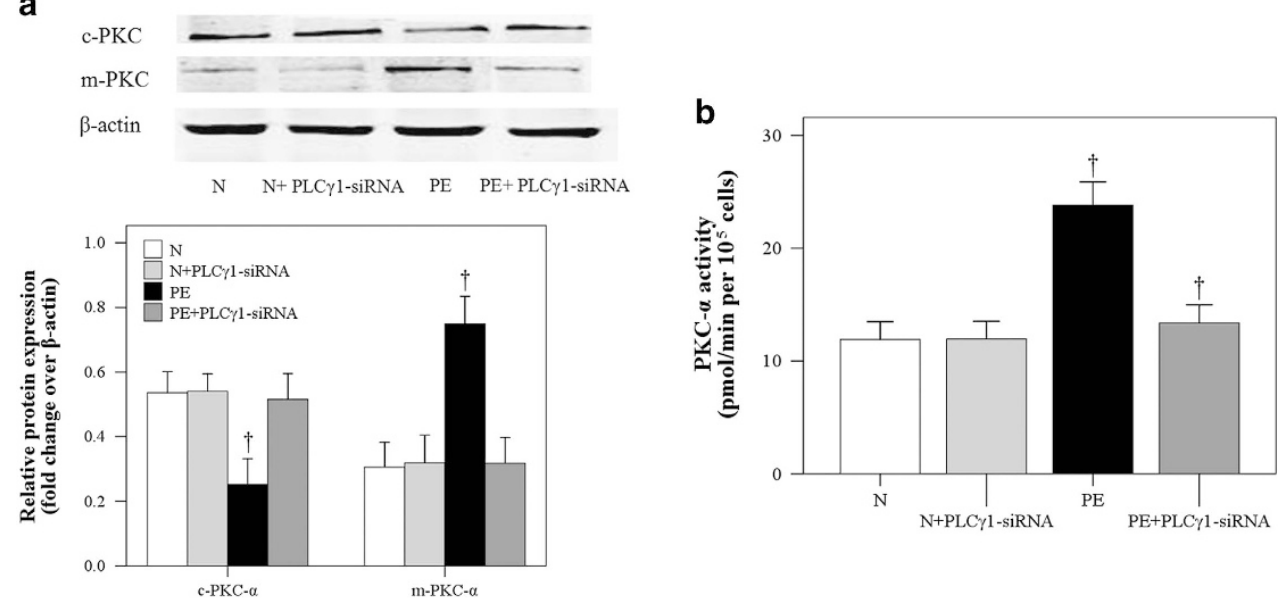

C
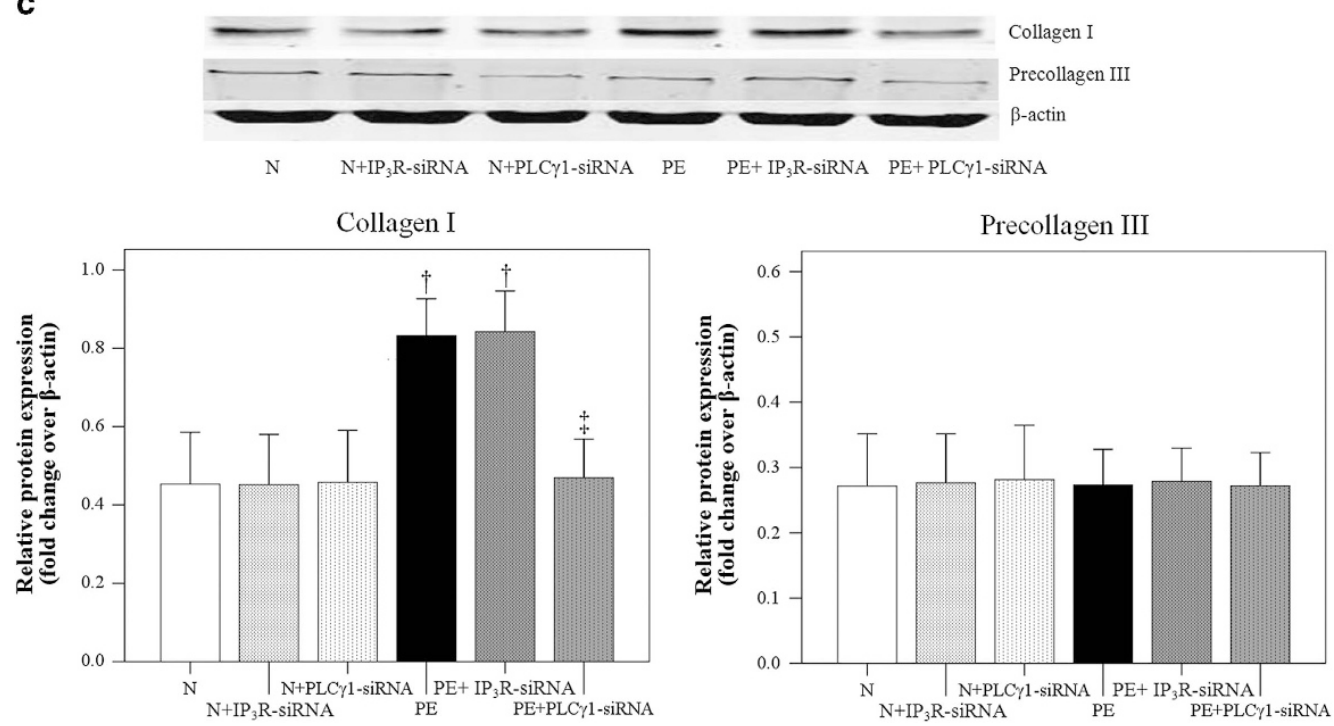

Figure 6 Effects of preeclampsia (PE) serum on protein kinase $\mathrm{C}-\alpha(\mathrm{PKC}-\alpha)$ expression and activity, as well as collagen expression by cocultured human umbilical artery smooth muscle cells (HUASMCs). (a) Cytosolic and membrane PKC- $\alpha$ (c-PKC- $\alpha$ and m-PKC- $\alpha$, respectively) expression. ${ }^{\dagger}$ Significantly different compared with the other three groups, $P<0.05$. (b) PKC- $\alpha$ activity. ${ }^{\dagger}$ Significantly different compared with the other three groups, $P<0.05$. (c) Collagen I and procollagen III expression in cocultured HUASMCs treated with normal (N) and PE sera without and with phospholipase $\mathrm{C}-\gamma 1$ (PLC- $\gamma 1$ ) small interfering RNA (siRNA) or 1,4,5-trisphosphate receptor (IP ${ }_{3} R$ ) siRNA. Data are presented as the mean \pm s.d. of 20 samples per group. ${ }^{\dagger}$ Significantly different compared with the first three groups ( $\mathrm{N}, \mathrm{N}$

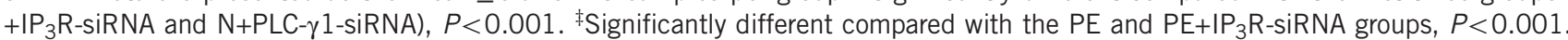

trans-acting factors responsible for increased type I collagen expression in PE. Increased thrombin, basic fibroblast growth factor and TNF- $\alpha$ levels have also been reported in PE and may induce smooth muscle cell proliferation. ${ }^{47,48}$ Thus, further studies will be conducted to identify the factor(s) responsible for the effects of PE sera on HUASMCs proliferation, ECM expression and function.

PE serum contains many ligands that can potentially activate other PLC isozymes to generate $\mathrm{IP}_{3}$ in HUASMCs. Although PLC- $\gamma 1$ knockdown reduced IP ${ }_{3} \mathrm{R}$ levels to that of the normal group, which suggests that it is the major form in these cells, other PLC isozymes may still be present. Thus, further studies will assess the PLC isozyme expression profiles in our HUASMC primary cultures.
In conclusion, vasoactive substances in $\mathrm{PE}$ serum may induce the deposition of the ECM through the activation of PLC- $\gamma 1$, which thereby results in the vascular dysfunction associated with PE. The elucidation of the role of the PLC- $\gamma 1$ PKC- $\alpha$ pathway in HUASMCs may help understand the etiology of PE and provide new therapeutic targets for the prevention and treatment of $\mathrm{PE}$.

\section{CONFLICT OF INTEREST}

The authors declare no conflicts of interest.

\section{ACKNOWLEDGEMENTS}

We acknowledge the support provided by Dr Alex F Chen and his colleagues from the Department of Surgery at the University of Pittsburgh, School of Medicine. This study was supported by the 
National Natural Science Foundation of China (31101065) to RZJ and the Shanghai Science and Technology Committee (10411966500) to YCT.

1 Steegers EA, von Dadelszen P, Duvekot JJ, Pijnenborg R. Pre-eclampsia. Lancet 2010; 376: 631-644.

2 Sibai BM. Diagnosis and management of gestational hypertension and preeclampsia. Obstet Gynecol 2003; 102: 181-192.

3 Mostello D, Catlin TK, Roman L, Holcomb WL Jr, Leet T. Preeclampsia in the parous woman: who is at risk? Am J Obstet Gynecol 2002; 187: 425-429.

4 Jiang R, Teng Y, Huang Y, Gu J, Li M. 431 cases of severe preeclampsia: diagnosis, treatment, and pregnancy outcome. Chin J Birth Health Heredity 2012; 20: 76-79.

5 Jiang RZ, Chen HP, Xu XY. Inhibitory effects of polymyxin B on NF-kappaB activation and expression of procollagen I, III in pre-eclamptic umbilical artery smooth muscle cells. Chin Med J (Engl) 2006; 119: 384-390.

6 Cho HM, Choi SH, Hwang KC, Oh SY, Kim HG, Yoon DH et al. The Src/PLC/ $\mathrm{PKC} / \mathrm{MEK} / \mathrm{ERK}$ signaling pathway is involved in aortic smooth muscle cell proliferation induced by glycated LDL. Mol Cells 2005; 19: 60-66.

7 Chandra A, Angle N. VEGF inhibits PDGF-stimulated calcium signaling independent of phospholipase C and protein kinase C. J Surg Res 2006; 131: 302-309.

8 Fan C, Su Q, Li Y, Liang L, Angelini DJ, Guggino WB et al. Hypoxia-induced mitogenic factor/FIZZ1 induces intracellular calcium release through the PLC-IP(3) pathway. Am J Physiol Lung Cell Mol Physiol 2009; 297: L263-L270.

9 Wynne BM, Chiao CW, Webb RC. Vascular smooth muscle cell signaling mechanisms for contraction to angiotensin II and endothelin-1. J Am Soc Hypertens 2009; 3: 84-95.

10 Le J. Obstetrics and Gynecology 7th edn. People's Health Publishing House: Beijing, China, 2008.

11 Jiang R, Teng Y, Huang Y, Gu J, Li M. Protein kinase C-alpha activation induces NF-kappaB-dependent VCAM-1 expression in cultured human umbilical vein endothelial cells treated with sera from preeclamptic patients. Gynecol Obstet Invest 2009; 69: 101-108.

12 Jiang $\mathrm{R}$, Chen $\mathrm{H}$. A preliminary study on PKC signal transduction in the mechanisms of placental vascular lesions in patients with pregnancyinduced hypertension syndrome. Chin Obstet Gynecol 2004; 39: 185-186.

13 Jiang R, Yan S, Teng Y, Huang Y, Gu J, Li M. Effect of preeclampsia serum on human uterine spiral artery smooth muscle cell apoptosis in a coculture model with cytotrophoblasts. Gynecol Obstet Invest 2012; 73: 201-210.

14 Stanislaus A, Bakhtiar A, Salleh D, Tiash S, Fatemian T, Hossain S et al. Knockdown of PLC-gamma-2 and calmodulin 1 genes sensitizes human cervical adenocarcinoma cells to doxorubicin and paclitaxel. Cancer Cell Int 2012; 12: 30

15 Mietus-Snyder M, Friera A, Glass CK, Pitas RE. Regulation of scavenger receptor expression in smooth muscle cells by protein kinase $\mathrm{C}$ : a role for oxidative stress. Arterioscler Thromb Vasc Biol 1997; 17: 969-978.

16 Marín-Vicente C, Nicolás FE, Gómez-Fernández JC, Corbalán-García S. The Ptdlns (4,5) P2 ligand itself influences the localization of PKCalpha in the plasma membrane of intact living cells. J Mol Biol 2008; 377: 1038-1052.

17 Higuchi S, Ohtsu H, Suzuki H, Shirai H, Frank GD, Eguchi S. Angiotensin II signal transduction through the AT1 receptor: novel insights into mechanisms and pathophysiology. Clin Sci (Lond) 2007; 112: 417-428.

18 Murphy SR, LaMarca BB, Cockrell K, Granger JP. Role of endothelin in mediating soluble fms-like tyrosine kinase 1 -induced hypertension in pregnant rats. Hypertension 2010; 55: 394-398.

19 Goel SA, Guo LW, Shi XD, Kundi R, Sovinski G, Seedial S et al. Preferential secretion of collagen type 3 versus type 1 from adventitial fibroblasts

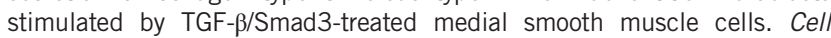
Signal 2013; 25: 955-960.

20 Romanowicz L, Galewska Z. Extracellular matrix remodeling of the umbilical cord in pre-eclampsia as a risk factor for fetal hypertension. J Pregnancy 2011; 2011: 542695.

21 Zhou H, Chen S, Wang L, He Q, Fan X. Regulation of the expression of pulmonary arterial collagen by protein kinase $\mathrm{C}$ and breviscapine in chronic hypoxic rats. Zhonghua Jie He He Hu Xi Za Zhi 2002; 25: 347-351.

22 Hori Y, Yoshioka K, Kanai K, Hoshi F, Itoh N, Higuchi S. Spironolactone decreases isoproterenol-induced ventricular fibrosis and matrix metalloproteinase-2 in rats. Biol Pharm Bull 2011; 34: 61-65.
23 Galewska Z, Bankowski E, Romanowicz L, Gogiel T, Wolanska M, Jaworski S. Preeclampsia-associated reduction of cathepsin D activity in the umbilical cord. Clin Chim Acta 2005; 351: 177-184.

24 Li W, Mata KM, Mazzuca MQ, Khalil RA. Altered matrix metalloproteinase2 and -9 expression/activity links placental ischemia and anti-angiogenic sFIt-1 to uteroplacental and vascular remodeling and collagen deposition in hypertensive pregnancy. Biochem Pharmacol 2014; 89: 370-385.

25 Jiang RZ, Huang YJ, Gu JH, Mu WH, Chen HP. Effects of nuclear factorkappaB decoy oligodeoxynucleotide on the function of human umbilical artery smooth muscle cells induced by umbilical sera in preeclampsia. Zhonghua Fu Chan Ke Za Zhi 2007; 42: 87-91.

26 Osherov AB, Gotha L, Cheema AN, Qiang B, Strauss BH. Proteins mediating collagen biosynthesis and accumulation in arterial repair: novel targets for anti-restenosis therapy. Cardiovasc Res 2011; 91: 16-26.

27 Woolfolk EA, Eguchi S, Ohtsu H, Nakashima H, Ueno H, Gerthoffer WT et al. Angiotensin II-induced activation of p21-activated kinase 1 requires $\mathrm{Ca}^{2+}$ and protein kinase C\{delta\} in vascular smooth muscle cells. Am J Physiol Cell Physiol 2005; 289: C1286-C1294.

28 Goel SA, Guo LW, Liu B, Kent KC. Mechanisms of post-intervention arterial remodelling. Cardiovasc Res 2012; 96: 363-371.

29 Kundi R, Hollenbeck ST, Yamanouchi D, Herman BC, Edlin R, Ryer EJ et al. Arterial gene transfer of the TGF-beta signalling protein Smad3 induces adaptive remodelling following angioplasty: a role for CTGF. Cardiovasc Res 2009; 84: 326-335.

30 Smith SC, Baker PN, Symonds EM. Placental apoptosis in normal human pregnancy. Am J Obstet Gynecol 1997; 177: 57-65.

31 Park JK, Kang MY, Kim YH, Jo HC, Shin JK, Choi WJ et al. PKC delta in preeclamptic placentas promotes Bax dissociation from 14-3-3 zeta through 14-3-3 zeta phosphorylation. Placenta 2008; 29: 584-592.

32 Snetkov VA, Thomas GD, Teague B, Leach RM, Shaifta Y, Knock GA et al. Low concentrations of sphingosylphosphorylcholine enhance pulmonary artery vasoreactivity: the role of protein kinase $\mathrm{C}$ delta and $\mathrm{Ca}^{2+}$ entry. Hypertension 2008; 51: 239-245.

33 Hirano K. Current topics in the regulatory mechanism underlying the $\mathrm{Ca}^{2+}$ sensitization of the contractile apparatus in vascular smooth muscle. J Pharmacol Sci 2007; 104: 109-115.

34 Schönfelder G, Fuhr N, Hadzidiakos D, John M, Hopp H, Paul M. Preeclampsia is associated with loss of neuronal nitric oxide synthase expression in vascular smooth muscle cells of the human umbilical cord. Histopathology 2004; 44: 116-128.

$35 \mathrm{Kim}$ J, Kim YJ, Lee R, Moon JH, Jo I. Serum levels of zinc, calcium, and iron are associated with the risk of preeclampsia in pregnant women. Nutr Res 2012; 32: 764-769.

36 Farzin L, Sajadi F. Comparison of serum trace element levels in patients with or without pre-eclampsia. J Res Med Sci 2012; 17: 938-941.

37 Steinert JR, Poston L, Mann GE, Jacob R. Abnormalities in intracellular $\mathrm{Ca}^{2+}$ regulation in fetal vascular smooth muscle in pre-eclampsia: enhanced sensitivity to arachidonic acid. FASEB J 2003; 17: 307-309.

38 Krupp J, Boeldt DS, Yi FX, Grummer MA, Bankowski Anaya HA, Shah DM et al. The loss of sustained $\mathrm{Ca}^{2+}$ signaling underlies suppressed endothelial nitric oxide production in preeclamptic pregnancies: implications for new therapy. Am J Physiol Heart Circ Physiol 2013; 305: H969-H979.

39 Chen Q, Zhang Y, Tong M, Wu M, Snowise S, Stone P et al. Pre-treatment with calcium prevents endothelial cell activation induced by multiple activators, necrotic trophoblastic debris or IL-6 or preeclamptic sera: possible relevance to the pathogenesis of preeclampsia. Placenta 2013; 34: 1196-1201.

40 Green J, Assady S, Nakhoul F, Bick T, Jakobi P, Abassi Z. Differential effects of sera from normotensive and hypertensive pregnant women on $\mathrm{Ca}$ (2+) metabolism in normal vascular smooth muscle cells. J Am Soc Nephrol 2000; 11: 1188-1198.

41 Dechanet C, Fort A, Barbero-Camps E, Dechaud H, Richard S, Virsolvy A. Endothelin-dependent vasoconstriction in human uterine artery: application to preeclampsia. PLoS ONE 2011; 6: e16540.

42 Sharma D, Singh A, Trivedi SS, Bhattacharjee J. Role of endothelin and inflammatory cytokines in pre-eclampsia - a pilot North Indian study. Am J Reprod Immunol 2011; 65: 428-432.

43 Eto H, Biro S, Miyata M, Kaieda H, Obata H, Kihara T et al. Angiotensin II type 1 receptor participates in extracellular matrix production in the late stage of remodeling after vascular injury. Cardiovasc Res 2003; 59: 200-211.

44 Liu G, Wang H, Ou D, Liao D. Endothelin-1, an important mitogen of smooth muscle cells of spontaneously hypertensive rats. Chin Med J 2002; 115: 750-752.

45 Yahiaoui L, Villeneuve A, Valderrama-Carvajal H, Burke F, Fixman ED. Endothelin-1 regulates proliferative responses, both alone and 
synergistically with PDAGF, in rat tracheal smooth muscle cells. Cell Physiol Biochem 2006; 17: 37-46.

46 Jain A, Olovsson M, Burton GJ, Yung HW. Endothelin-1 induces endoplasmic reticulum stress by activating the PLC-IP(3) pathway: implications for placental pathophysiology in preeclampsia. Am J Pathol 2012; 180: 2309-2320.

47 Chan AK, Kalmes A, Hawkins S, Daum G, Clowes AW. Blockade of the epidermal growth factor receptor decreases intimal hyperplasia in ballooninjured rat carotid artery. J Vasc Surg 2003; 37: 644-649.

48 Liu XM, Reyna SV, Ensenat D, Peyton KJ, Wang H, Schafer Al et al. Platelet-derived growth factor stimulates LAT1 gene expression in vascular smooth muscle: role in cell growth. FASEB J 2004; 18: 768-770. (c) (i) (2) (2) This work is licensed under a Creative Commons Attribution-NonCommercial-ShareAlike

3.0

Unported License. The images or other third party material in this article are included in the article's Creative Commons license, unless indicated otherwise in the credit line; if the material is not included under the Creative Commons license, users will need to obtain permission from the license holder to reproduce the material. To view a copy of this license, visit http://creativecommons.org/licenses/by-nc-sa/3.0/ 